\title{
Numerical study on the revised rules for minimum degree of shear connection in propped and unpropped steel-concrete composite beams
}

\author{
C. Odenbreit \& V. Vigneri \\ University of Luxembourg, Luxembourg-Kirchberg, Luxembourg
}

\begin{abstract}
The work presents a numerical study that focuses on steel-concrete composite beams using ductile headed stud shear connectors. The objective is to check the suitability of the proposed revised EN 1994-1-1 rules for the minimum degree of shear connection. Therefore, a non-linear 3D finite element model of simply supported composite beams was developed and validated against the analytical values of the plastic bending design resistance. The parametric study consists of 10 configurations where the relative slip at slab-beam interface was carefully investigated at different degrees of shear connection and propping conditions. Specifically, the slip at the minimum degree of shear connection shall not exceed the limit of $6 \mathrm{~mm}$ defined as the characteristic slip of ductile connector according to EN 1994-1-1. The results showed that the revised rules for unpropped beams delivers conservative results whereas one case with propped conditions exhibit a maximum slip significantly higher than $6 \mathrm{~mm}$.
\end{abstract}

\section{INTRODUCTION}

According to current design rules of EN 1994-1-1 (British Standards Institution, 2004), ductile shear connectors (e.g. headed studs) in composite beams allow the use of partial shear connection in plastic design as confirmed by past experimental and numerical studies (Johnson \& Molenstra, 1991). However, to limit the occurring slip between the steel beam and the concrete slab within the characteristic slip capacity of the connector (at least $6 \mathrm{~mm}$ ) at ultimate and serviceability limit state (SLS and ULS), a minimum degree of shear connection shall be guaranteed. CEN/TC250/SC4.PT3 proposed a revised version of the design rules relative to the minimum degree of shear connection $\eta_{\min }$ accounting for the partial utilization of the beam and propping construction procedure. However, there are only few studies focused on the occurring slip in unpropped composite beams with symmetrical sections. Therefore, the authors performed a numerical study aiming to fill this gap and to justify the reduction factors proposed in the new design proposal for minimum degree of shear connection.

\section{PROPOSED EQUATION FOR MINIMUM DEGREE OF SHEAR CONNECTION}

Based on the design proposal of CEN/TC250/SC4.PT3 and further investigations, the following equations have been recently proposed for beams subjected to sagging bending moment, taking into account their partial utilization with the factor $\delta_{I}$.

For steel sections having equal flanges, propped construction and ductile shear connectors: 


$$
L_{e} \leq 25: \eta \geq\left[1-\underset{L_{e}>25}{\left.\left(\frac{355}{f_{y}}\right)\left(0.75-0.03 L_{e}\right)\right] \cdot \delta_{1}^{2} ; \eta \geq 0.4}\right.
$$

With:

$$
\delta_{1}=\frac{M_{E d}}{0.95 M_{p l, R d, \eta}} \geq 0.8
$$

Where $L_{e}$ is the distance in sagging bending between points of zero bending, $M_{E d}$ is the acting design bending moment and $M_{p l, R d, \eta}$ indicates the bending moment resistance depending on the degree of shear connection $\eta$.

In addition to the positive influence of the utilization of the beam, the required degree of shear connection for unpropped beams can be further reduced based on the self-weight to resistance ratio with the factor $k_{\text {unpr }}$, as follows:

$$
\begin{gathered}
L_{e} \leq 25: \eta \geq\left[1-\left(\frac{355}{f_{y}}\right)\left(0.75-0.03 L_{e}\right)\right] \delta_{1}^{2} \cdot k_{\text {unpr }} ; \eta \geq 0.3 \\
L_{e}>25: \eta \geq 1
\end{gathered}
$$

With:

$$
\begin{gathered}
k_{\text {unpr }}=\left\{\begin{array}{cl}
1.0 & \text { for } \frac{M_{E d}}{M_{P l, R d, \eta}} \geq 0.95 \\
\left(1-\delta_{2}\right) & \text { for } \frac{M_{E d}}{M_{P l, R d, \eta}}<0.95
\end{array}\right. \\
\delta_{2}=\frac{M_{s w, E d}}{M_{p l, R d}} \leq 0.15
\end{gathered}
$$

Where $M_{s w, E d}$ is the bending moment due to the self-weight of the composite beam and $M_{p l, R d}$ is the bending moment resistance for full shear connection (i.e. $\eta=1.0$ ). For the investigation of the slip displacement, a finite element (FE) model was developed and it is presented in section 3 .

\section{DESCRIPTION OF THE FINITE ELEMENT MODEL}

\subsection{General}

The FE model presented in this chapter bases on the experience gained over the past research studies where the behaviour of composite beams with partial shear connection was investigated. Among these, the recent RFCS research projects DISCCO (Lawson, et al., 2017) and REDUCE (European Commission: Directorate-General for Research and Innovation, 2020) as well as the work made by CEN/TC250/SC4.PT3 are mentioned. The software ABAQUS 2017 (Dassault Systèmes Simulia, 2014) was used to develop a finite element (FE) model able to simulate the mechanical behaviour of a composite beam. The structural system reproduced in the study was a simply supported beam under uniformly distributed load as shown in Figure 1. The FE model, consist of 3 main parts: (i) concrete slab, (ii) steel beam and (iii) a set of shear connectors that transfer the longitudinal shear force between them, as detailed in Table 1.

\subsection{Material properties}

In the FE modelling of composite beams using composite slabs with profiled steel sheeting, only the effective height of the concrete above the rib of the steel sheeting was considered. Notwithstanding that the material damage was not considered in this model, the "Concrete 

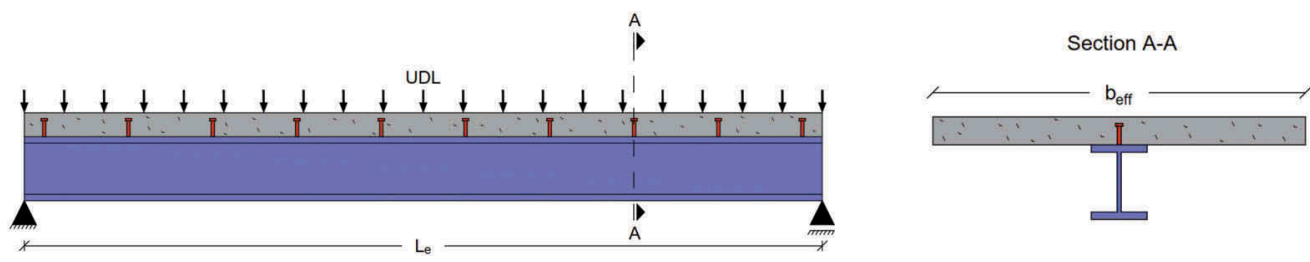

Figure 1. Structural system considered in the study.

Table 1. Instances and material of the FE model.

\begin{tabular}{llll}
\hline & Instance & Element type & Material \\
\hline (i) & Concrete slab & Solid (C3D8R) & Concrete Damaged Plasticity \\
(ii) & Steel beam & Solid (C3D8R) & 3D von Mises plasticity model \\
(iii) & Shear connectors & Fastener & Uniaxial non-linear law \\
\hline
\end{tabular}

Damaged Plasticity" (CDP) model available in ABAQUS was applied to the concrete. The main material parameter are given in Table 2 . They include: modulus of elasticity $E_{c m}$, Poisson's ratio $v$, dilation angle $\psi$, flow potential eccentricity $e$, ratio of compressive strength under biaxial loading to uniaxial compressive strength $f_{b o} / f_{c}$ and the ratio of the second stress invariant on the tensile meridian to that on the compressive meridian $K_{c}$. The values assigned to the CDP plasticity parameters are also given in Table 2 . The concrete behaviour under compression was modelled according to the design parabola-rectangle uniaxial law of EN 1992-1-1. As already done in a similar study (Aggelopoulos, et al., 2018), the tensile strength was taken as approximately $10 \%$ of the corresponding compressive strength of the concrete. Beyond this point, a full plastic plateau was assumed in the uniaxial stress-strain law. The steel beam was reproduced through solid continuum elements (C3D8R). To ease the mesh modelling procedure, the web-flange junctions were neglected. The beam material follows the Von Mises plasticity criterion with a bilinear stress-strain law with a very small hardening slope of less than $\mathrm{E}_{\mathrm{s}} / 200$. The modulus of elasticity was taken as $210000 \mathrm{MPa}$ while the Poisson's ratio was 0.3 .

Finally, the shear connectors were modelled through the ABAQUS feature *FASTENER which allows to connect two points with a directional spring law and to attach these points to the selected surfaces. First, the attachment points were created on the top flange of the steel beam along the longitudinal direction with a constant spacing of $250 \mathrm{~mm}$. Then, the corresponding attached points were created on the bottom surface of the "effective" concrete slab (projection along normal direction) and coupled with the respective attachment points on the top flange, see Figure 2.

To reproduce the behaviour of actual shear connectors in composite beams, only the relative displacement in the longitudinal direction of the coupled points was released using the type of mechanical constraint "Slot" and "Align" in *CONNECTOR SECTION.

The uniaxial load-slip curve along the longitudinal direction of each connector was defined through a bi-linear uniaxial load-slip curve. It was assumed that the ultimate design resistance

Table 2. Plasticity parameters of the CDP model (Dassault Systèmes Simulia, 2014).

\begin{tabular}{llllll}
\hline Property & $\begin{array}{l}\text { Dilation } \\
\text { angle } \psi\left[\left[^{\circ}\right]\right.\end{array}$ & $\begin{array}{l}\text { Eccentricity } \\
e[-]\end{array}$ & $\begin{array}{l}\text { Biaxial to axial } \\
\text { strength ratio } \\
f_{b 0} / f_{c}[-]\end{array}$ & Coefficient $K_{C}[-]$ & $\begin{array}{l}\text { Viscosity parameter } \\
\mu[-]\end{array}$ \\
\hline Value & 38 & 0.1 & 1.16 & 0.667 & $1 \times 10-5$ \\
\hline
\end{tabular}




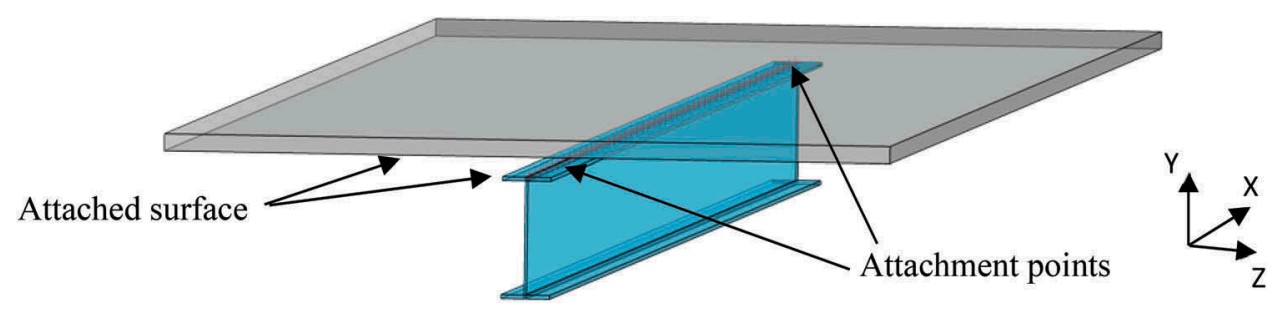

Figure 2. Attachment points of the FE model corresponding to the location of the shear connectors.

of the shear connectors $P_{R d}$ is achieved at a slip displacement of $1 \mathrm{~mm}$. Beyond this value, the connector has a full plastic behaviour. The resistance $P_{R d}$ was modified in each configuration to fit the needed degree of shear connection, as explained in Chapter 4.

\subsection{Mesh modelling, boundary conditions and load application}

The concrete slab and the steel beam were modelled with continuum solid elements with reduced integration (C3D8R). A sensitivity analysis was performed to check the most efficient mesh size. The average mesh size of the concrete slab was defined as $150 \mathrm{~mm}$ with 4 layers along the vertical direction. The mesh of the steel beam was approximately $50 \mathrm{~mm}$. It was also checked that a denser mesh does not improve the accuracy of the FE model. To reproduce the simply supported conditions given in Figure 1, one of the supports was restricted to translate in the three principal directions $(\mathrm{X}, \mathrm{Y}$ and $\mathrm{Z}$ ) whereas only the longitudinal displacement along $\mathrm{X}$ was allowed in the other support. In both cases, the rotation around the axis $\mathrm{Z}$ was released. These boundary conditions were implemented in ABAQUS by coupling reference points to the ends of the steel beam. Furthermore, to account for the effect of the contiguous slabs in the transversal direction, symmetric boundary conditions in the transversal direction were included along the lateral edges of the slab. In this way, any lateral displacement was prevented. Finally, the load was applied on a partitioned strip located on the surface of the top flange through the ABAQUS feature *SURFACE TRACTION. The load direction was defined through a vector to ensure that the load applies along the vertical direction throughout the whole simulation.

\subsection{Unpropped conditions}

To reproduce the loading stages of unpropped composite beams, two different sub-models were initially created: the first considers only the steel beam (before concreting) while the other includes the concrete slab as well as the shear connectors (after concreting). The former model was needed to compute the stress field of the steel beam after applying the load due to the self-weight of the beam and the slab. After that, this stress field was imported in the second model via the feature *PREDEFINED FIELD-STRESS available in Abaqus, in Step 1 . During the step 2, the additional "imposed" load was increasingly applied on the composite system until failure. Such procedure for modelling numerically the unpropped conditions were also used in several previous studies (Aggelopoulos, et al., 2018).

\section{PARAMETRIC STUDY}

Once the FE model was successfully validated for propped and unpropped beams against the analytically obtained values of the bending design resistance, several configurations were analysed within their typical range of application. The span length ranges between 10 and $21 \mathrm{~m}$ while the depth-to-span ratio of the steel profile vary around 25, typically considered for the design of composite beams. All the cases refer to composite slabs with $80 \mathrm{~mm}$ deep 
Table 3. Data of the configurations analysed.

\begin{tabular}{|c|c|c|c|c|c|c|c|c|c|}
\hline \multirow[b]{2}{*}{ N. } & \multirow[b]{2}{*}{ Case } & \multirow{2}{*}{$\frac{\text { Span }}{\mathrm{m}}$} & \multirow{2}{*}{$\begin{array}{l}\text { Steel } \\
\text { grade }\end{array}$} & \multirow{2}{*}{$\begin{array}{l}\text { Steel } \\
\text { section }\end{array}$} & \multirow{2}{*}{$\begin{array}{l}\text { Concrete } \\
\text { class }\end{array}$} & \multirow{2}{*}{$\begin{array}{l}\begin{array}{l}\text { Slab } \\
\text { width }\end{array} \\
\mathrm{mm}\end{array}$} & \multirow{2}{*}{$\begin{array}{l}\begin{array}{l}\text { Eff. slab } \\
\text { depth }\end{array} \\
\text { mm }\end{array}$} & \multirow{2}{*}{$\begin{array}{l}\text { Rib } \\
\text { height }\end{array}$} & \multirow{2}{*}{$\begin{array}{l}M_{s w} / M_{p l, R d} \\
-\end{array}$} \\
\hline & & & & & & & & & \\
\hline 1 & $10-300-\mathrm{A}$ & 10 & S355 & IPE 300 & C30/37 & 2500 & 70 & 80 & 0.16 \\
\hline 2 & $10-400-\mathrm{A}$ & 10 & S355 & IPE 400 & C30/37 & 2500 & 70 & 80 & 0.10 \\
\hline 3 & $12-400-\mathrm{A}$ & 12 & S355 & IPE 400 & C30/37 & 3000 & 70 & 80 & 0.16 \\
\hline 4 & $12-500-\mathrm{A}$ & 12 & S355 & IPE 500 & C30/37 & 3000 & 70 & 80 & 0.11 \\
\hline 5 & $16-450-\mathrm{A}-27$ & 16 & S355 & IPE 450 & C30/37 & 2700 & 70 & 80 & 0.29 \\
\hline 6 & 16-600-A & 16 & S355 & IPE 600 & C30/37 & 4000 & 70 & 80 & 0.17 \\
\hline 7 & $18-500-\mathrm{A}$ & 18 & S355 & IPE 500 & C30/37 & 4500 & 70 & 80 & 0.33 \\
\hline 8 & $18-600-\mathrm{A}$ & 18 & S355 & IPE 600 & C30/37 & 4500 & 70 & 80 & 0.23 \\
\hline 9 & 21-600-A & 21 & S355 & IPE 600 & C30/37 & 5250 & 70 & 80 & 0.35 \\
\hline 10 & 21-750-A & 21 & S355 & IPE 750 & C30/37 & 5250 & 70 & 80 & 0.27 \\
\hline
\end{tabular}

profiled sheeting (transverse to the beam) and a total slab depth of $150 \mathrm{~mm}$. Only the effective portion of the slab (i.e. $70 \mathrm{~mm}$ deep) was considered in the FE model. For all configurations listed in Table 3, the resistance of shear connectors was adjusted to achieve different degree of shear connection ranging from 0.2 to 1.0 according to:

$$
P_{R d}(\eta)=\frac{N_{c}}{n} \eta
$$

Where $N_{c}$ is the total compression force in the concrete slab and $n$ is the number of studs in the shear length of the beam. For each case, both propped and unpropped conditions were simulated.

\section{EVALUATION OF THE RESULTS FOR DUCTILE CONNECTORS}

\subsection{General}

To check the suitability of the design proposal for the minimum degree of shear connection, the values of the slip of the shear connections obtained in the parametric study was determined at an applied load level leading to a mid-span acting bending moment equal to $95 \%$ of the plastic bending design resistance $\left(M_{p l, R d, \eta}\right)$ of the beam. This value was analytically calculated in accordance with the plastic rigid theory of EN 1994-1-1 for partial shear connection using the design properties of the steel and concrete. Such procedure is consistent with the assumptions made in the original calibration of the shear connection rules of current EN 1994-1-1 (Aribert, 1997). Due to the different application of the load on unpropped beams, the cases with propped conditions exhibited higher slip values. Specifically, the slip reduction due to the unpropped construction is significant and it typically ranges between $15 \%$ and $50 \%$ depending on the load level.

\subsection{Evaluation of the slip values}

In order to check that the slip limit is not exceeded according to the proposed design equations in section 2, (a) each system was analysed (b) for different degrees of shear connection and (c) the output of the simulation were extracted at different utilization factor UF. Finally, (d) all the simulations were run for propped and unpropped conditions. The value of the end-slip s was plotted at different levels of $\mathrm{UF}=M_{E d} / M_{p l, R d, \eta}$ from each run. This procedure was repeated for different degree of shear connection $\eta$ until the $\eta-s$ curves were complete, see Figure 3. 


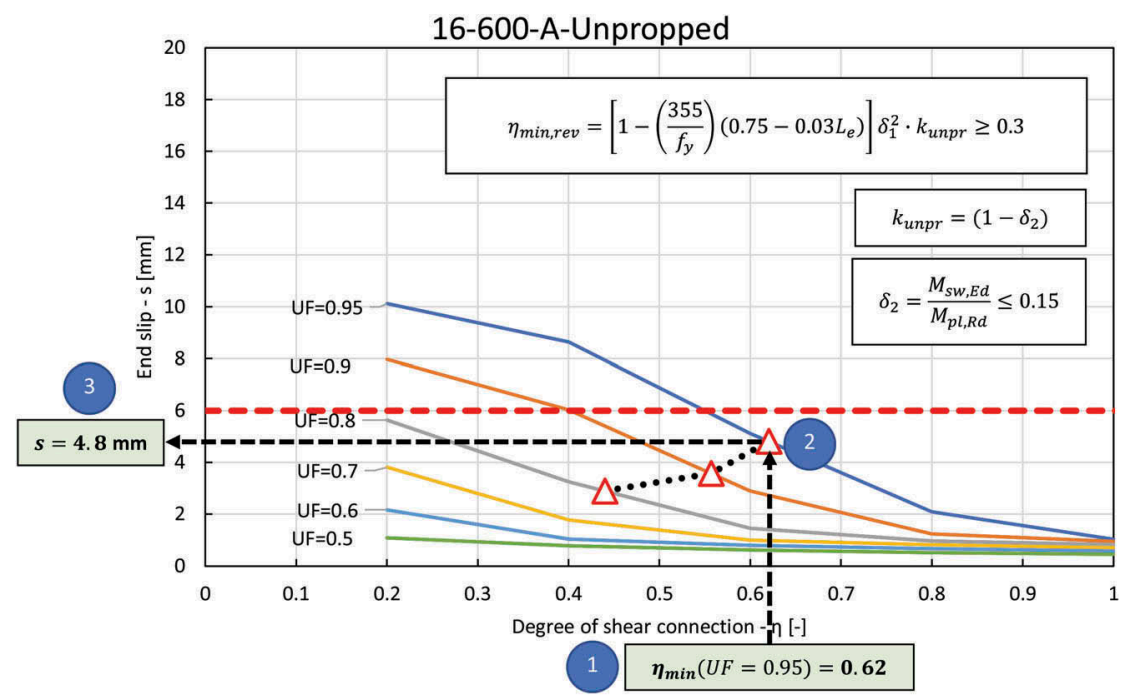

Figure 3. Example of slip - degree of shear connection curves showing the occurring slip at the design minimum degree of shear connection for ductile connectors at $\mathrm{UF}=0.95$.

(1) Once the curves are generated, the minimum degree of shear connection $\eta_{\min }$ was firstly calculated for a given value of UF according to the proposed design rules for ductile studs. In case of propped beams, Eq. (1) shall be used while Eq. (3) apply to unpropped beams.

(2) The intersection with the corresponding curve gives the value of the occurring slip at $\eta_{\min }$.

(3) After repeating the procedure for different load levels $(\mathrm{UF}=0.95,0.9,0.8 \ldots)$ the values of the occurring slip are displayed as red triangles in Figure 3.

If these values are lower than $6 \mathrm{~mm}$, the design rules can be safely applied to the configuration considered. The values of the slip at the minimum degree of shear connection were plotted for all cases considered in Figure $4 \mathrm{a}$ and Figure $4 \mathrm{~b}$, for propped and unpropped conditions at $\mathrm{UF}=0.9$ and $\mathrm{UF}=0.95$ respectively. According to these results, the revised rules for minimum degree of shear connection for unpropped beams can be safely applied whereas only one case of the propped configurations shows a maximum slip of ca. $8.6 \mathrm{~mm}$.

a)

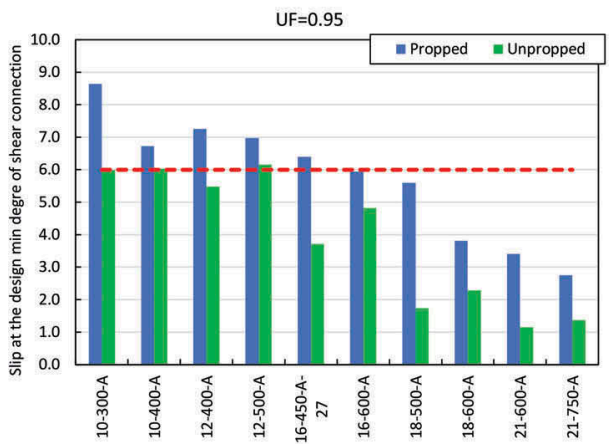

b)

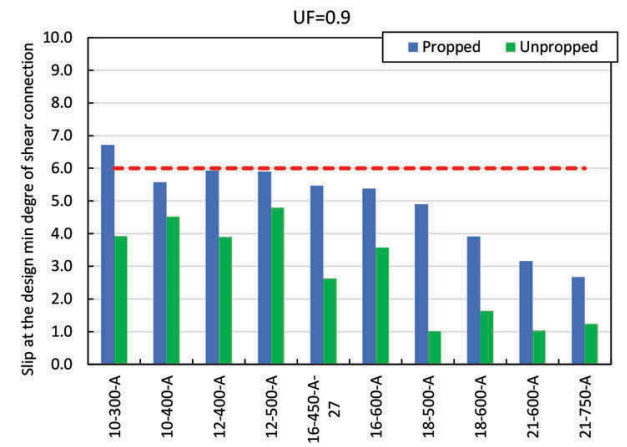

Figure 4. Occurring slip at the design minimum degree of shear connection for ductile connectors at: a) $\mathrm{UF}=0.95$ and $\mathrm{b}) \mathrm{UF}=0.9$. 


\section{CONCLUSIONS AND OUTLOOK}

A finite element model of propped and unpropped composite beam with symmetrical beams was presented and validated against analytical results. Then, a parametric study was performed to assess the maximum occurring slip at the minimum degree of shear connection according to the proposed revised rules that accounts for the positive effect of the unpropped conditions.

Based on the study presented, the slip at the minimum degree of shear connection according to revised rules for unpropped beams with ductile connectors is lower than $6 \mathrm{~mm}$. Therefore, this design solution can be safely applied to unpropped composite beams. On the other side, only one of the propped configurations shows a maximum slip noticeably higher than $6 \mathrm{~mm}$.

However, to provide a more reliable evidence of the suitability of the design rules, further simulations of composite beams using solid slabs are foreseen. Furthermore, the approach presented to assess the design rules for the minimum degree of shear connection may be extended to propped and unpropped composite beams with asymmetrical and/or cellular steel beam.

\section{REFERENCES}

Aggelopoulos, E., Couchman, G. \& Lawson, M., 2018. Minimum degree of shear connection in composite beams in buildings. Valencia, s.n.

Aggelopoulos, E., Hanus, F. \& Lawson, M., 2018. Shear connection requirements for composite cellular beams. Valencia, s.n.

Aribert, J. M., 1997. Analyse et formulation pratique de l'influence de la nuance de l'acier du profile sur le degre minimum de connexion partielle d'une poutre mixte. Construction Métallique, Volume 3, pp. $39-55$.

British Standards Institution, 2004. EN 1992-1-1: 2004 Eurocode 2 - Design of concrete structures Part 1-1: General rules and rules for buildings. London: s.n.

British Standards Institution, 2004. EN 1994-1-1: 2004 Eurocode 4 - Design of composite steel and concrete structures Part 1-1: General rules and rules for buildings. London: s.n.

CEN-TC250-SC4, 2018. CEN-TC250-SC4-N1893: 1.1 - SC4.T3_FIN_DOC_EN1994-1-1_6.6.1.1\& 6.6.1.2_eta, s.1.: s.n.

Dassault Systèmes Simulia, 2014. Abaqus Analysis User's Guide v6.14, s.1.: s.n.

European Commission: Directorate-General for Research and Innovation, 2020. Reuse and demountability using steel structures and the circular economy (REDUCE), Brussels: s.n.

Johnson, R. P. \& Molenstra, N., 1991. Partial shear connection in composite beams for buildings. Proceedings of the Institution of Civil Engineers, 91(4), pp. 679-704.

Lawson, M. et al., 2017. Development of improved shear connection rules in composite beams - Final Report, s.1.: s.n. 